\title{
Leaching fraction, soil salinity, and drainage efficiency
}

\author{
M. E. Grismer
}

\begin{abstract}
Measuring the efficiency of a subsurface irrigation drainage system is complicated by a number of factors, including the irrigation water's salinity, the soil's inherent salinity, and the degree to which saline drainwater migrates laterally in a shallow water table.
\end{abstract}

Salinity in the soil rootzone is a major concern for farmers of irrigated crops in arid regions. Typically, the irrigation water available in such regions contains measurable, sometimes substantial amounts of salts that must be leached from the soil after irrigation. The soil profile may also contain soluble minerals that contribute both to the salinity hazard to crops and to the salt load of agricultural drainwater. Irrigation water salts aren't always carried away in drainwater, either; some of those salts may be deposited in the soil. All plants require some salt-borne nutrients (i.e., $\mathrm{Ca}, \mathrm{K}$, etc.), but not at the levels considered here. To control salinity in the soil profile, farmers apply irrigation water in excess of crop water requirements. Some install subsurface drainage systems that collect and remove part of the excess water once it has leached the rootzone, preventing already shallow water tables from rising any nearer to the soil surface.

To maintain favorable rootzone salinity, growers depend on a combination of processes, including rootzone leaching and chemical precipitation. Leaching involves applying enough excess water to translocate some of the salts out of the rootzone. The amount of excess water required depends partly on the chemical composition of the water, insofar as that influences salt precipitation and the water's ability to carry salts.

Put simply, a grower can maintain the rootzone salt balance by applying enough excess water to carry the sameamount of salt out of the soil as the water itself brings in. Here, the ratio of the rootzone drainage volume to theapplied watervolumeis similar to the ratio of applied water salinity to drainwater salinity, otherwise known as the leaching fraction (LF). Such a simple case of

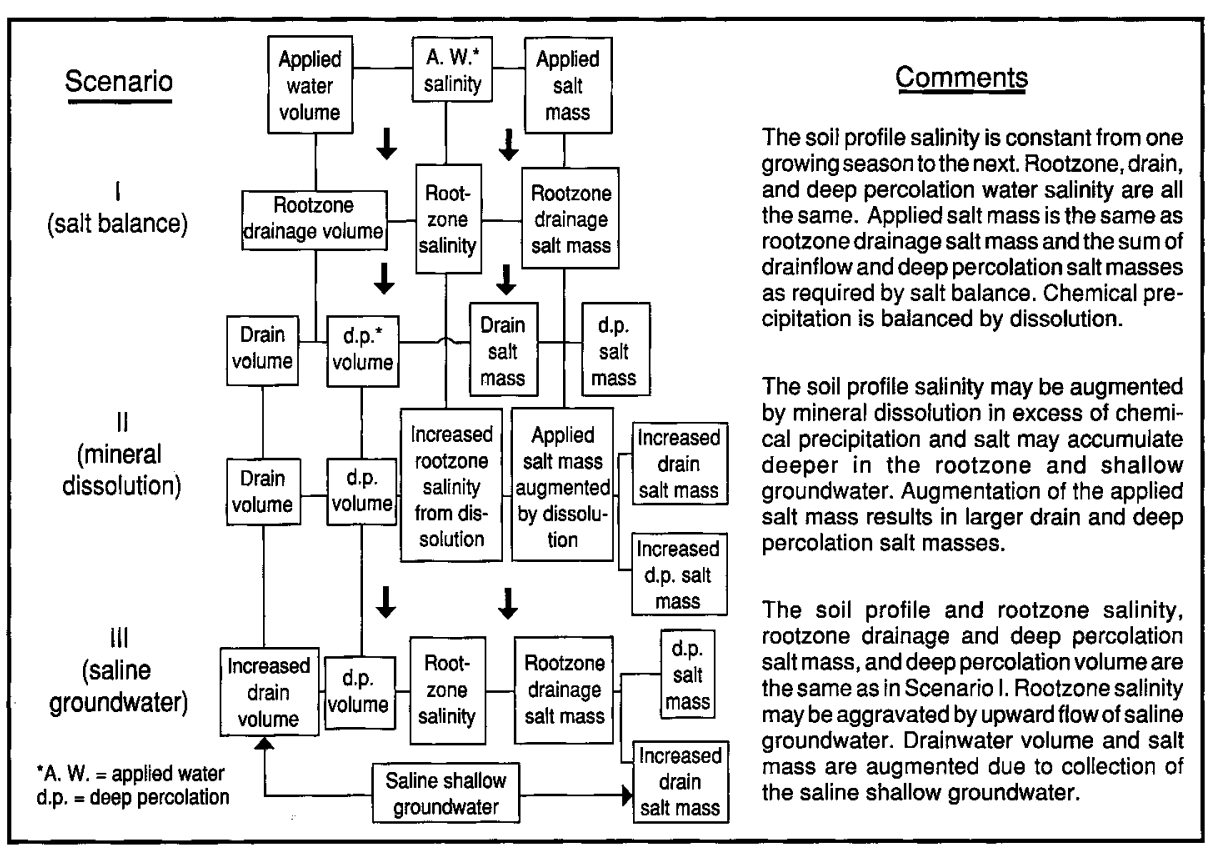

Fig. 1. Three simplified scenarios of the saltwater processes involved in rootzone leaching and drainage. salt balance seldom occurs in the field, but it helps us define LF and illustrates some basic processes involved in rootzone leaching. For the salt balance approach to succeed, the salts applied in irrigation water must be removed from the rootzone by various salt "sinks" (e.g., chemical precipitation, collection of excess irrigation by a subsurface drainage system, and deep percolation of rootzone drainage).

The balance of salts is often determined on the basis of the salt load of the applied water and that of the subsurface drainwater discharge. But besides saline rootzone waters, subsurface drainage systems in the San Joaquin and Imperial valleys collect saline waters from deeper in the soil. The total salt load leaving the Broadview and Imperial Valley water districts in drainwater is roughly twice the load applied in irrigation water, despite subsurface drainage systems that collect only part of the rootzone drainwaterafteranirrigation. Thesubsurface drainage systems tend to collect any available groundwater, making the rootzone salt balancedifficultif notimpossibletocalculate withoutadditional data. This report presents three soil-water flow factors that affect salt balancedeterminations: LF, soil salinity, and the drainage efficiency (DE) of subsurface systems.

\section{Salt leaching and drainage}

Figure 1 summarizes thesoil-water processes involved in rootzone leaching and drainage shown schematically in figure 2, giving three simplified scenarios that describe the leaching process. Other possible scenarios combine elements of these three.

In scenario I, salt balance is maintained in the rootzone even though salts may accumulate in the shallow groundwater, depending on the drains' efficiency and the rate of lateral movement for the shallow groundwater. In this case, salt accumulation may occur in the shallow groundwater when the salts in the applied water translocate to the groundwater. (The salinity of shallow groundwater may also increase as a result of evaporation at the water table.) For this case, LF can be based on the ratio of the salinity of the applied water to the salinity of the rootzone drainage, or the rootzone drainage volume to applied water volume. 


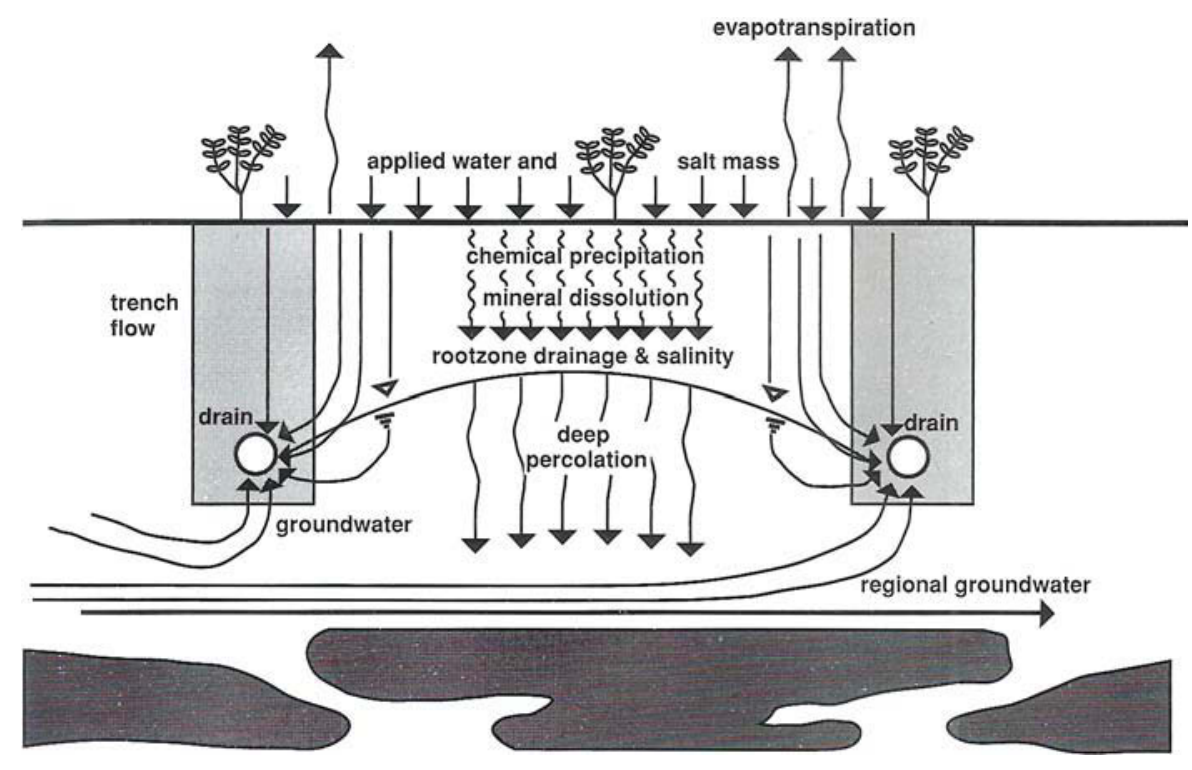

Fig. 2. Schematic illustration of the flow of water through soil with respect to salt leaching and rootzone drainage.

Rootzone drainage volume is then the product of LF and the volume of applied water. The drainage efficiency can be determined from the ratio of the collected drainwater salt mass to the applied salt mass, or the ratio of collected drainwater volume to rootzone drainage volume. A DE of less than $100 \%$ results in the addition of rootzone drainage water and salt load to the shallow groundwater. Depending on the flow patterns of the shallow groundwater, the additional salinity may require removalatsome time.

In scenario II, dissolved minerals add to the rootzone's salinity and to the potential forsalt to accumulate deeper in the rootzone. Increased rootzone salinity also puts greater salt loads in drainwater and in deep-percolated water. A grower can balance the soil salts by applying enough water to leach the soil's dissolved salts and the salts in the applied water. Partial leaching, involving less water than the salt balance calculations would imply, may suffice, depending on the crop's salt tolerance. As minerals continue to dissolve and leach, the degree to which soil salts can be extracted will decrease throughout the soil profile. If rootzone drainage is insufficient toleach the dissolved salts that have not precipitated, they will accumulate deeper in the rootzone.

The salinity ratio from scenario I gives too small an LF value for scenario II, underestimating the rootzonedrainage volume and the volume of excess irrigation needed to leach the salts, depending on the crop's salt tolerance. Other, more involved calculations are needed. In scenario II, we can only determine the correct $\mathrm{DE}$ by measuring the drainwater volume and the rootzone

\begin{tabular}{|c|c|c|c|c|c|c|c|}
\hline \multirow[b]{2}{*}{ Year } & \multicolumn{3}{|c|}{ Applied water } & \multicolumn{3}{|c|}{ Drainwater } & \multirow[b]{2}{*}{$\begin{array}{l}\text { Leaching } \\
\text { fraction* }\end{array}$} \\
\hline & Volume & $\begin{array}{l}\text { Salt } \\
\text { load }\end{array}$ & Salinity & Volume & $\begin{array}{l}\text { Salt } \\
\text { load }\end{array}$ & Salinity & \\
\hline \begin{tabular}{|l|l|l|}
1939 \\
1940 \\
1941 \\
1942 \\
1943 \\
1944 \\
1945 \\
1946 \\
1947 \\
1948
\end{tabular} & $\begin{array}{c}1,000 \mathrm{~m}^{3} t \\
30.8 \\
131.6 \\
106.8 \\
87.0 \\
68.0 \\
97.8 \\
101.7 \\
92.6 \\
93.5 \\
29.0\end{array}$ & $\begin{array}{r}\text { tons } \\
27.1 \\
121.9 \\
68.0 \\
71.4 \\
41.1 \\
66.7 \\
78.0 \\
76.7 \\
78.1 \\
23.9\end{array}$ & $\begin{array}{l}\mathrm{mg} / \mathrm{L} \\
799 \\
847 \\
592 \\
751 \\
557 \\
625 \\
700 \\
754 \\
759 \\
749\end{array}$ & $\begin{array}{c}1,000 \mathrm{~m}^{3} t \\
1.23 \\
8.02 \\
8.02 \\
6.29 \\
5.55 \\
20.6 \\
22.9 \\
17.5 \\
7.65 \\
2.96\end{array}$ & \begin{tabular}{r|} 
tons \\
11.2 \\
66.9 \\
71.4 \\
56.4 \\
46.6 \\
212.7 \\
231.7 \\
180.3 \\
67.0 \\
22.2
\end{tabular} & $\begin{array}{l}\mathrm{mgl} \\
8,606 \\
7,593 \\
8,068 \\
8,179 \\
7,566 \\
9,393 \\
9,166 \\
9,331 \\
7,945 \\
6,786\end{array}$ & \begin{tabular}{r|}
$\%$ \\
9.3 \\
11.2 \\
7.3 \\
9.2 \\
7.4 \\
6.7 \\
7.6 \\
8.1 \\
9.6 \\
11.0
\end{tabular} \\
\hline $\begin{array}{l}1987-88 \\
\text { July } 1988\end{array}$ & $\begin{array}{l}7.84 \\
2.60\end{array}$ & $\begin{array}{l}6.34 \\
2.21\end{array}$ & - & $\begin{array}{l}2.95 \\
0.017 \ddagger \\
0.080 \ddagger\end{array}$ & $\begin{array}{l}25.1 \\
1.42 \ddagger \\
0.64 \ddagger\end{array}$ & - & $\begin{array}{r}\overline{9} .6 \\
10.5\end{array}$ \\
\hline
\end{tabular}

drainage volume. Estimates based on the ratio of drainwatersaltmass to applied water salt mass would overestimate the performance of the subsurface drainage system.

Shallow groundwater quality in scenarios Iand II can bedegraded by a soil or subsurface drainage system with a poor DE, significant lateral movement of groundwater, and water table evaporation. Often, the poor quality of a groundwater is a result of these factors.

Scenario III is similar to scenario I, but with greater drainflows and salt loads caused by salinegroundwater. Estimates of LFbased on drainwater salinity would be artificially low, and DE estimates based on drainflows would be too high. Our field measurements from the Imperial Valley illustrate scenario III, and the difficulty of determining LF and $\mathrm{DE}$ on the basis of salt balance concepts.

\section{Field measurements}

The persistent salinity problems of heavy Imperial Valley soils have long made them the objects of study. A 10-year study (1939 to 1948 inclusive) on 18 acres of what would become the Imperial Valley Research and Extension Center led researchers to conclude that continuous ponding was necessary to adequately leach excess salts from the rootzone. In 5 of that study's 10 years, the 6foot-deep subsurface drainage system removed more salts than were applied (table 1). In 2 years of those 5 , the drainage system collected nearly three times the salt mass applied, even though the same amount of water was applied as in years when the drainage system collected less salt mass than was applied. The lack of additional information about the salinity of the soil and of the shallow groundwater prevents any quantitative evaluation of the benefits to reduction of soil salinity of the 10-year leaching period.

Data in table 1 clearly show that even during the 10 years of leaching, the drainwater's net salt load exceeded that of theapplied water, sosteady-statesalt balance conditions do not appear to exist. For comparative purposes, however, we calculated the leaching fraction for each year of the study under the assumption that a rootzone salt balance did exist.

Themean LFwas about9\%: theminimum (about 7\%) occurred when the drainage system carried an excess salt load, and the maximum (about $11 \%$ ) when the drainage system removed less salt than was applied. LFs for more recent studies, calculated with the presumption of salt balance, haveyielded similar values. Forty years after the study, the salinity of applied water and drainwater in an adjacent field indicates an LF of about $10 \%$. Despite years of leaching and despite some deterioration in the quality of applied water, the calculated salt balance LFremains about the same. 
In order to evaluate the salt leaching and drainage conditions more accurately, we conducted a field study of soil-water movement in a clay soil profile in Imperial Valley. For 8 months (October 1987 to May 1988), we regularly monitored applied water and drainwater volumes and salinities. For 1 month (July 1988), we collected intensive field data following an irrigation event. Pertinent data from these studies are summarized at the bottom of table 1 . We found that the drainagesystem maintained asteady base flow of approximately 9 liters per minute, originating in the shallow groundwater system (fig. 3 ).

Based on measurements that include the base flows, the drainage system appears to extract about $38 \%$ of the applied water and 2.4 times the applied salt load. This suggests a net leaching of salts from the soil, but data show that the soil's salinity has not changed for at least 25 years.

During the 1-month monitoring period, the base flow contributed $324 \mathrm{~m}^{3}$ to the drainwater volume and $2,488 \mathrm{~kg}$ to the salt load. Disregarding base flows, the DE based on salt load removal is $29.1 \%$ ([582 $\mathrm{kg} \div 2,003$ $\mathrm{kg}] \times 100 \%$ ), which implies a total rootzone drainage of $274 \mathrm{~m}^{3}\left(79.6 \mathrm{~m}^{3} \div 0.291\right)$ and an LF of $10.5 \%$ ([274 $\left.\left.\mathrm{m}^{3} \div 2,601 \mathrm{~m}^{3}\right] \times 100 \%\right)$. If we include base flows, the drains remove over 1.5 times the salt load applied to the field. Because the salinity of this field has not changed in many years, the excess salt load must not be related to irrigations of this particular field - its origin must be elsewhere. The shallow water table is probably part of a regional groundwater system salinized by rootzone drainage from other fields.

Similarly, by disregarding base flows for the initial 8-month study period, we get a DE for this period of $22.3 \%$, implying a total rootzone drainage of $750 \mathrm{~m}^{3}$ and an LF of $9.6 \%$. These revised values are more consistent with those from the 25 days following the July 1988 irrigation. The smaller DE and LF values for the 8-month period may result from the infrequency of irrigation and the limited amount of rainfall.

Geohydrologic assessment and the field data collected from the Imperial Valley field indicate that salt leaching processes in this field are close to those in scenario III. The rootzone appears to be salt-balanced, with about one-quarter of the applied salt load removed directly by the subsurface drainage system. Part of the remaining salt load that accumulates in the shallow groundwater may also be collected by the drains, or it may move away with normal regional groundwater flows.

Chemical analyses of the irrigation water and drainwater also help us understand leaching and DE. The data in table 2 summarize these results in terms of ionic ratios for flows from the old drainage system and
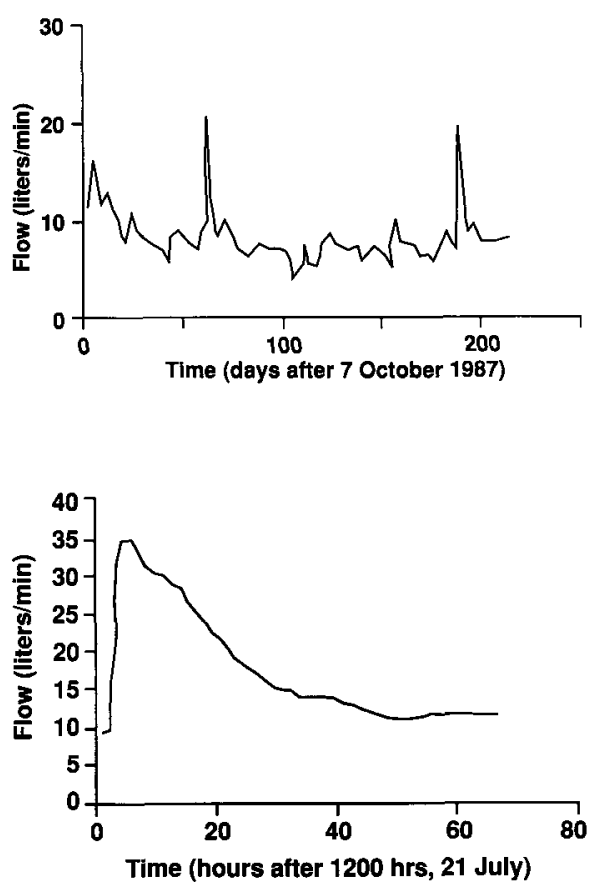

Fig. 3. Drain flows for October 1987 through May 1988.

from its newer replacement. Varying ionic ratios point to a further complexity of salt leaching: notallsalts areleached in equivalent amounts. Previous measurements (California Agriculture May-June 1988) indicated that the old drainage system collected less rootzone drainage than the new. This condition is also reflected in the smaller ionic ratios for drainwater from the old as compared to the new drains.

The salinity ratios for the new drains and the collector drain are about $10 \%$, close to the LF already calculated. Magnesium and sulfate ionic ratios are also similar. This all suggests there is a sort of a salt balance for this soil profile. Ideally, the chloride ratio would approximate the steady-state saltbalance LF, as it is unaffected by dissolution

\begin{tabular}{|c|c|c|c|}
\hline \multirow[t]{2}{*}{ Ratio } & $\begin{array}{c}\text { Old } \\
\text { drains } \\
(6 / 86)\end{array}$ & $\begin{array}{c}\text { New } \\
\text { drain* } \\
(7 / 88)\end{array}$ & $\begin{array}{l}\text { Collector } \\
\text { drain } \\
(7 / 88)\end{array}$ \\
\hline & 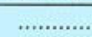 & $\ldots . . . \% \ldots \ldots$ & ........... \\
\hline Salinity & 6.9 & $8.7-11.1$ & 10.1 \\
\hline Chloride & 2.2 & $4.3-7.8$ & 7.5 \\
\hline Sulfate & 6.6 & $8.9-10.0$ & 9.1 \\
\hline Sodium & 4.0 & $7.3-8.3$ & 8.7 \\
\hline Potassium & - & $20.0-24.5$ & 22.2 \\
\hline Calcium & 13.9 & $14.3-19.5$ & 21.6 \\
\hline Magnesium & 5.2 & $8.7-11.1$ & 9.9 \\
\hline
\end{tabular}

- Several samples were taken after irrigation during which salinity and ionic concentrations typically de clined then increased. The values represent the maximum range of measured values. and precipitation reactions. In this instance, however, the actual ratio appears to be slightly less than the calculated LF. This difference may reflect the variable nature of leaching. Relatively large ratios for calcium and potassium may indicate precipitation and limited cation-exchange reactions in the soil profile. Additional leaching and mineral dissolution in the rootzone (scenario II) would require that we move more water through the soil profile.

\section{Summary and conclusions}

In many irrigated regions, soil salinity, leaching fraction, and drainage efficiency can be considered as related salinity control parameters. Defining the relationship between these parameters, however, requires informationabouthow watermoves through the local soil profile. For example, on the basis of irrigation and drainwater salinities, Imperial Valley soils have an LF of about $10 \%$. Though this valueisclose to that derived from calculations of soil water movement, we cannot assume $a$ priori that it can be used toestimateactual rootzone drainagevolumes or drainage efficiencies. We would first need additional information on salinity variations in the soil profile and other sources of drainwater.

When we know that a salt balance exists, $\mathrm{LF}$ is a convenient tool for estimating rootzone drainage. Together with data on subsurface drainwater volumes, we can use LF to calculateDE. Conversely, in theabsence of additional data DEs of less than $100 \%$ do not necessarily imply an accumulation of salts in the rootzone.

The salinity of shallow groundwater directly effects the salt load removed by subsurface drainage systems. Drainwater salt loads in excess of those in the applied water do not necessarily represent additional leaching or mineral dissolution in the soil profile - they may just as easily represent saline shallow groundwater resulting from prior salt leaching, from salts leached in other fields within a regional shallow water table, or from evaporative concentration of salts. Reducing the rootzone drainage volume through improved irrigation efficiency may havelittle effect on the drainwater's salt load for several years if that salt load reflects shallow groundwater salinity. It is therefore not surprising that at the water district scale the drainwater salt load exceeds that of the applied water. Such a discrepancy may be a necessary component in the eventual removal of excess groundwater salinity and the achievement or maintenance of a district-wide salt balance.

M. E. Grismer is Associate Professor of Water Science and Associate Agricultural Drainage Engineer with the Departments of Agricultural Engineering and Land, Air, and Water Resources, UC Davis. 